\title{
$Y \bar{A}-B T \bar{A} L-L \bar{A} D \bar{I} F \bar{I} L-S A M \bar{A} W \bar{A} T . .$. NOTAS SOBRE ANTIGUAS VERSIŌNES ÁRABES DEL «PADRE NUESTRO»
}

\author{
Juan Pedro Monferrer SAlA \\ Universidad de Córdoba
}

Más de un lustro ha pasado desde que el gran maestro Massignon, sin duda una de las personalidades más singulares en el ámbito del arabismo internacional, escribiera su conocido trabajo sobre el hadịt al-ruqya que él consideraba la primera versión árabe del «Padre nuestro» ${ }^{1}$. Sostenía allí Massignon que este hadiz, datado a finales del siglo I de la Hégira o finales del siglo vir de J. C., reflejaba una versión árabe del «Padre nuestro» que, como oración profiláctica empleada para curar el cálculo de vejiga (hașāt al-bawl), se extendió rápidamente en círculos musulmanes. Señalaba, además, que los textos de poetas cristianos de los siglos VI al IX no habían conservado ninguna oración, fuera del tipo que fuese, de la Iglesia traducida al árabe, añadiendo a ello que las citas de los Evangelios ${ }^{2}$ que nos había conservado la literatura musulmana antigua (littérature musulmane ancienne) no podían probar la existencia de una traducción íntegra (bien del siriaco o del griego) de los Evangelios, o del Diatessaron ${ }^{3}$, con anterioridad al siglo $\mathrm{x}^{4}$. Todo ello, sobre todo en lo concerniente al ámbito litúr-

\footnotetext{
1 Massignon, L., «Le "hadith al-ruqya" musulman. Première version arabe du "Pater"», Massignon, L., Opera Minora. Textes recueillis, classés et presentés avec une bibliographie par Y. Moubarac. Sous le Patronage du Centre d'Études Dar El-Salam. 3 vols., Beirut, 1963, I, 92-96.

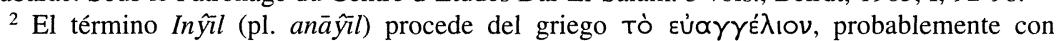
influencia del etiópico wangēl, cfr. Jeffery, A., The Foreign Vocabulary of the Qur'ān, Baroda, 1938, 71-72.

${ }^{3}$ Para las dos únicas ediciones que poseemos de la versión árabe esta obra: Ciasca, A., Tatiani Evangeliorum Harmoniae arabice, Roma, 1888 y Marmadji, A. S., Diatessaron de Tatien. Texte arabe établi, traduit en français, collationné avec les anciennes versions syriaques, suivi d'un évangéliaire diatessarique syriaque, Beirut, 1935. Acerca del autor árabe del Diatessaron, Baarda, T., «The Author of the Arabic Diatessaron», Baarda, T., et alii (eds.), Miscellanea Neotestamentica, Leiden, 1978, I, 61-103. Sobre el Diatessaron, Leclercq, H. «Diatessaron», Cabrol, F. y Leclercq, H. (eds.), Dictionnaire d'Archéologie Chrétienne et de Liturgie, París, 1920, IV/1, cols., 747-770; Kahle, P. E., The Cairo Genizah, Oxford, 1959 (2. ${ }^{a}$ ed.), 283-284, $297-$ 301 y 304-313; Peters, C., Das Diatessaron Tatians, 19-29 y 48-61; Metzger, B. M., The Early Versions of the New Testament. Their Origin, Transmission and Limitations, Oxford, 1977, 10-36. Trabajos sistemáticos sobre el mismo en Baarda, T., Essays on the Diatessaron, Kampen, 1994. Una valoración reciente es la de Joosse, P., «An Introduction to the Arabic Diatessaron», Oriens Christianus, 83 (1999), 72-129.

${ }^{4}$ Massignon, L., «Le "hadith al-ruqya" musulman...», Massignon, L., Opera Minora, I, 92. Una pequeña cala en la literatura de tradición, sin rastro alguno del «Padre nuestro», la hizo
} 
gico, lo justificaba Massignon arguyendo que les apôtres chrétiens, jalousement attachés à leur liturgie en syriaque, s'obstinaient à ne pas enseigner à leurs nouveaux prosélytes leurs prières usuelles en langue arabe ${ }^{5}$.

El hadiz al que nos acabamos de referir y que Massignon supone la primera versión al árabe del «Padre nuestro» aparece compilado por vez primera en el Sunan de Abū Dāwūd (m. 275/888-9) y siglos más tarde por al-Dahabī en su Kitāb al-'Uluww, las dos únicas fuentes que anteponen al matn el pertinente isnād. Esta cadena de transmisores permitía a Massignon remontar el hadiz al menos hasta Layt b. Sa'd (m. 175/791) ${ }^{6}$, después de desechar al converso judío medinés al-Qurazī $(\mathrm{m} .118 / 736)^{7}$ por razones de índole religiosa ${ }^{8}$, lo cual le hubiese permitido adelantar su datación.

El matn del hadiz, que acabaría siendo «adaptado» poco después en ambientes šĩ 'íes ${ }^{9}$, es el siguiente:

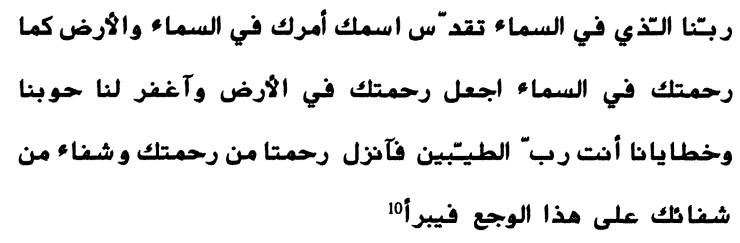

El trabajo del irrepetible maestro francés, impecable en su factura y sólido en su procedimiento, resulta, por el contrario, frágil en cuanto al planteamiento sobre el que basa su exposición. Cierto es que material, tanto coránico como procedente de la tra-

Goldziher, I., Muslim Studies. Edited by S. M. Stern. Translated from the German by C. R. Barber and S. M. Stern, Londres, 1971, II, 346-362; cfr. en esta misma línea y sin que se documente el «Padre nuestro», su trabajo posterior «Neutestamentliche Elemente in der Traditionslitteratur des Islam», Oriens Christianus, II (1902), 390-397. El eco de la oratio dominica que pretendía ver Asín como base en un hadiz del siglo IX también está lejos de poder probar la existencia de una versión árabe con anterioridad a dicho hadiz, Asín Palacios, M., «Logia et Agrapha Domini Jesu apud moslemicos scriptores, asceticos praesertim, usitata collegit, vertit, notis instruxit», Patrologia Orientalis, XIII/3 (1919), 355-356 (n. $\left.{ }^{\circ} 11\right)$.

${ }^{5}$ Massignon, L., «Le "hadith al-ruqya" musulman...», Massignon, L., Opera Minora, I, 92.

${ }^{6}$ Sobre este célebre tradicionista, Encyclopédie de l'Islam. Nouvelle Édition (2. ${ }^{a}$ ed.), LeidenParís, 1960, V, 716-717 (A. Merad).

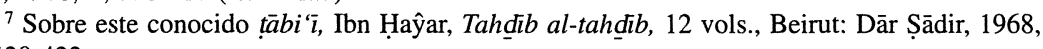
IX, 420-422.

${ }^{8}$ Massignon, L., «Le "hadith al-ruqya" musulman...», 95.

${ }^{9}$ Massignon, L., op. cit., 96.

${ }^{10}$ Massignon, L., op. cit., 92, que lo reproduce en transcripción con caracteres latinos. 
dición, era empleado, entre otros, con fines profilácticos y sanadores. Ahora bien, la cuestión que nos concierne en este punto es saber si este hadítal-ruqya entró en la tradición musulmana adaptado ya como oración empleada en «ambientes de sanación» o todavía como texto del «Padre nuestro» que acaba amoldándose más tarde a tales prácticas sanadoras. El planteamiento de Massignon apunta al primer caso, aunque no parezca consciente de la problemática que implica la disyuntiva que sugerimos:

[...] parmi les hadîth attribués au Prophète, apparaît une version arabe du Pater, rapidement diffusé dans les milieux musulmans, à cause de la réputation des chrétiens comme médecins, en qualité de «ruqya» [...] ${ }^{11}$

Si el texto entró en la tradición musulmana (y hay que entender, de acuerdo con el planteamiento de Massignon, que por primera vez en árabe) convertido ya en oración profiláctica, es evidente que dicho texto como tal ya no era el «Padre nuestro». La segunda posibilidad, por lo tanto, resulta del todo imposible por el hecho de que el texto recibido por la tradición musulmana, aun procediendo de un «Padre nuestro», es incorporado como un texto retocado y distinto de aquél, desprovisto de los elementos teológicos característicos y fundamentales del mismo. Además, el hecho de llegar a suponer un probable desarrollo del texto dentro de la propia tradición musulmana, esto es, que entrando como «Padre nuestro» acabase evolucionando a la forma del texto profiláctico que se nos ha conservado, carece de apoyatura documental y, desde el punto de vista textual, resulta difícil sostener. Con todo, de lo que no hay duda es de que el asunto más importante radica en torno al propio texto. Éste, tal como ha pasado a la literatura de tradición musulmana, ha quedado «mutilado», perdiendo como ya hemos dicho, todos los elementos teológicos que le son característicos, lo cual da pie a poder suponer que, tal vez, ya en los mismísimos círculos cristianos se confeccionase dicha oración de carácter profiláctico tomando como base al «Padre nuestro» y siguiendo el triple esquema de invocación-súplica-aplicación.

Hemos señalado más arriba que Massignon afirmaba que la antigua literatura musulmana no documentaba una traducción de los Evangelios al árabe con anterioridad al siglo $\mathrm{x}$. Si es verdad que el problema suscitado en torno a la primera traducción árabe de la Biblia -en época preislámica y en los momentos inmediatos a la aparición en escena del Profeta- plantea no pocos y serios incovenientes que por ahora parecen lejos de hallar una solución aceptable ${ }^{12}$ (aun

${ }^{11}$ Massignon, L., op. cit., 92.

${ }^{12}$ Cfr. las síntesis recogidas por Graf, G., Geschichte der christlichen arabischen Literatur. 5 vols., Módena, 1996 (=Ciudad del Vaticano, 1944-1953), I, $27-52$ y Widengren, G., Muḥammad, the Apostle 
cuando la tesis liturgista, lanzada por Baumstark ${ }^{13} \mathrm{y}$ desarrollada por Shahīd ${ }^{14}$, es la que tiene más visos de seguir adelante), no es menos cierto que la historia del texto de los Evangelios en árabe se remonta, cuando menos, hasta finales del siglo IX.

De entre los manuscritos árabes que se nos han conservado del Nuevo Testamento ${ }^{15}$, las copias más antiguas se hallan contenidas en códices guardados en la laura de Santa Catalina del Monte Sinai ${ }^{16}$ : la más antigua de todas ellas de la que tenemos noticia, que incorpora traducciones del Nuevo Testamento, ha sido datada como perteneciente al siglo Ix. Dicha copia, conocida con la signatura Sinai Arabic Codex $151 / 110^{17}$, contiene un total de 269 folios en pergamino de $250 \mathrm{x}$ $175 \mathrm{~mm}$ que incluyen una versión árabe de las epístolas de Pablo, las epístolas Católicas y los Hechos de los Apóstoles en un códice que emplea un «tipo cali-

of God, and His Ascension (King and Saviour, V.), Uppsala-Wiesbaden, 1956, 151-161. Cfr. además, sobre esta problemática, Margoliouth, D. S., «Old and New Testaments in Muhammadanism», Hastings, J. (Ed.), Encyclopaedia of Religion and Ethics. 13 vols., Edimburgo, 1917, IX, 481 y De Goeje, M. J., «Quotations from the Bible in the Qorān and the Tradition», Kohut, G. A., (Ed.), Semitic Studies in Memory of Rev. Dr. Alexander Kohut, Berlín, 1897, 180-182; Ahrens, K., «Christliches im Qoran. Eine Nachlese», Zeitschrift der Deutschen Morgenländischen Gesellschaft, 84 (1930), 148-190; Vajda, G., «Observations sur quelques citations bibliques chez Ibn Qotayba», Revue des Études Juives, XCIX (1935), 68-80; Vööbus, A., Studies in the History of the Gospel Text in Syriac, Lovaina, 1951, 156-163; Lecompte, G., «Les citations de l'Ancien et du Nouveau Testament dans l'oeuvre d'Ibn Qutayba», Arabica, V (1958), 40-46; Kister, M. J., «Haddithū 'an banī isrā'îla wa-lā haraja. A Study of an Early Tradition», Kister, M. J., Studies in Jāhiliya and Islam, Aldershot, 1980, XIV, 235-236 y 238; Khoury, R. G., «Quelques réflexions sur les citations de la Bible dans les premières générations islamiques du premier et du deuxième siècles de l'Hégire», Bulletin des Études Orientales, XXIX (1977), 269-278; Somekh, S., «Biblical Echoes in Modern Arabic Literature», Journal of Arabic Literature, XXVI (1995), 186-188 y aparato crítico. Asimismo, Lüling, G., Über den Urkoran. Ansätze zur Rekonstruktion der vorislamisch-christlichen Strophenlieder im Koran, Erlangen, 1993 (2. ${ }^{\text {ed.), }} 347$ 400 ( $c f r$. al respecto Baumstark, A., «Jüdischer und christlicher Gebetstypus im Koran», Der Islam, 16 (1927), 229-248. También Lazarus-Yafeh, H., Intertwined Worlds. Medieval Islam and Bible Criticism, Princeton, 1992, 111-129 y Adang, C., Muslim Writers on Judaism and the Hebrew Bible: from Ibn Rabban to Ibn Hazm, Leiden-Nueva York-Colonia, 1996, espec. 110-138.

${ }^{13}$ Baumstark, A., «Das Problem eines vorislamischen christlichkirchlichen Schriftums in arabischer Sprache», Islamica, 4 (1931), 562-575; cfr. Peters, C., Das Diatessaron Tatians, 49.

${ }^{14}$ Cfr. los dos trabajos de Shahid, I., Byzantium and the Arabs in the Fourth Century, Washington, 1984, 435-443 y Byzantium and the Arabs in the Fifth Century, Washington, 1989, 422-458.

${ }^{15}$ Para un completo listado de éstos, Metzger, B. M., The Early Versions of the New Testament, 261-265; cfr. basado en el trabajo de Guidi, Hyvernat, H., «Arabes (Versions)», en: Vigouroux, F. (Dir.), Dictionnaire de la Bible, París, 1895, I, cols. 851-853.

${ }^{16}$ Para una valoración sobre los fondos árabes y turcos custodiados en este monasterio, Atiya, A. S., «The Arabic and Turkish Scrolls of Mount Sinai», en: Black, M.; Fohrer, G. (Eds.), In Memoriam Paul Kahle, Berlín, 1968, 10-16.

${ }^{17}$ Para la edición y traducción de las «Epístolas Paulinas», Staal, H., Mt. Sinai Arabic Codex 151, I. Pauline Epistles (CSCO. Scriptores Arabici, 40-41), 2 vols., Lovaina, 1983 y Staal, H., Mt. Sinai Arabic Codex 151, II. Acts and Catholic Epistles (CSCO. Scriptores Arabici, 42-43), Lovaina, 1984. 
gráfico transicional» entre el nasjī y el cúfico ${ }^{18}$. En el colofón ${ }^{19}$ de este manuscrito podemos leer que un escriba llamado Bišr al-Sirrī ${ }^{20}$ lo vertió al árabe, a partir del siriaco, en la ciudad de Damasco durante el mes de ramaḍān del año 253/867, es decir, una treintena de años antes de que se llevase a cabo la primera versión árabe de los Evangelios, esta última conocida como Sinai Arabic Codex $72 / 65$, realizada por Esteban de Ramla en el año 284/897 ${ }^{21}$, que incluye los cuatro Evangelios canónicos cuyas lecturas aparecen distribuidas siguiendo el ciclo litúrgico griego de la iglesia jerosolimitana ${ }^{22}$. Junto a esta versión, y dentro de las muestras más antiguas que se nos han conservado, tenemos fragmentos de la copia conocida como Vaticano Arabo 13 de la «Biblioteca Apostólica Vaticana», procedente de la laura jerosolimitana de $M a \bar{r} S \operatorname{sa} b \bar{a}$, situada en los aledaños de Jerusalén, del que en la actualidad sólo se nos conservan las epístolas paulinas y fragmentos de los Evangelios (Mt 1,1-28,11a; Mc 5,19-16,8 [la sección 6,9b-7,11 está detrás del fragmento de Lc] y Lc 3,31b-7,11a), habiéndose perdido los Salmos, los Hechos de los Apóstoles y lo que resta de los cuatro Evangelios y las epístolas ${ }^{23}$.

Exceptuando algún caso aislado, las versiones árabes de los Evangelios que se nos han conservado manuscritas atienden a una clasificación en cinco grupos textuales ${ }^{24}$. En una primera familia están las versiones realizadas a partir de un origi-

${ }^{18}$ Cfr. Atiya, A. S., The Arabic Manuscripts of Mount Sinai, Baltimore, 1955, 6 (n. $\left.{ }^{\circ} 151\right)$ y Kamil, M., Catalogue of all Manuscripts in the Monastery of St Catharine on Mount Sinai, Wiesbaden, 1970, 16 (n. $\left.{ }^{\circ} 110\right)$

${ }^{19}$ Acerca de las características que presentan los colofones, Troupeau, G., «Les colophons des manuscrits arabes chrétiens», Deroche, F.; Richard, F. (Dirs.), Scribes et manuscrits du MoyenOrient, París, 1997, 224-231.

${ }^{20}$ Sobre Bišr al-Sirrī, Nasrallah, J., «Deux versions melchites partielles de la Bible du IX ${ }^{\mathrm{e}}$ et du $\mathrm{X}^{\mathrm{e}}$ siècles», Oriens Christianus, 64 (1980), 203-206.

${ }^{21}$ Una reproducción facsímil de este colofón se encuentra en Padwick, C. E., «Al-Ghazali and the Arabic Versions of the Gospels. An unsolved Problem», Muslim World, 29 (1939), entre 134 y 135. Sobre Iștifanā 1-Ramblī, Griffith, S. H., «Stephen of Ramlah and the Christian kerygma in Arabic in 9th Century Palestine», Journal of Ecclesiastical History, 36 (1987), 23-45.

${ }^{22}$ Además de la Tesis leída en la «Catholic University of America», de Garland, A. G., An Arabic Translation of the Gospel According to Mark, Washington, 1979 (Griffith, S. H., «The Gospel in Arabic: an inquiry into its appearance in the first Abbasid century», Oriens Christianus, 65 [1985], 132, nota 20) contamos con una edición total que incorpora la traducción de Marcos y un completo estudio del mismo gracias a la Tesis Doctoral, todavía inédita, de Arbache, S., Une ancienne version arabe des Evangiles. Langue, texte et lexique, Burdeos: Université Michel de Montaigne (Bordeaux III), 1994 (Dirs.: Gérard Troupeau y Jacques Langhade).

${ }^{23}$ Griffith, S. H., «The Gospel in Arabic...», Oriens Christianus, 69 (1985), 131-132; para cuestiones relacionadas con los manuscritos, así como referencias a los Evangelios en árabe empleando un sentido retrospectivo, 131-167. También Griffith, S. H., «The monks of Palestine and the growth of Christian literature in Arabic», Muslim World, LXXVIII (1988), 17-20 y Shahīd, I., Byzantium and the Arabs in the Fifth Century, 422-430, 438-441 y 449-450.

${ }^{24}$ Guidi, I., «Le traduzioni degli Evangeli in arabo e in etiopico», Atti della R. Accademia dei Lincei, CCLXXXV/4 (1888), 5-28. 
nal griego; la segunda recoge las traducciones procedentes o corregidas sobre el texto de la Pešittă ; la tercera familia agrupa a aquellas copias hechas o corregidas a partir de versiones coptas; la cuarta familia acoge a las versiones procedentes de dos recensiones eclécticas distintas elaboradas por el Patriarcado de Alejandría durante el siglo XIII; la quinta familia, por último, contiene copias de carácter misceláneo, algunas de las cuales acabaron adoptando la forma de la prosa rimada clásica a imitación del Corán. A estas cinco familias puede añadirse una sexta familia formada por un corpus de versiones que han sido corregidas a partir de otras derivadas de una Vorlage diferente ${ }^{25}$.

Sin dejar de lado los fragmentos conservados en obras musulmanas ${ }^{26}$, a todas estas versiones de procedencia oriental, las más antiguas pertenecientes a la demarcación siria-palestinense ${ }^{27}$, tenemos que añadir aquellas específicamente occidentales siguiendo la denominación de gruppo occidentale dada por Guidi ${ }^{28}$, donde el texto base está formado por un texto latino, en principio elaborado a partir bien de la Vetus o de la Vulgata - cuando no conectado con alguna de estas dos tradiciones escriturarias latinas - que sin duda fueron empleadas en al-Andalus hasta el fin del Islam en la Península ${ }^{29}$.

${ }^{25}$ Guidi, I., «Le traduzioni degli Evangeli...», Atti della R. Accademia dei Lincei, CCLXXXV (1888), 5-27 y 30-32; cfr. las importantes colaciones de fragmentos (Mt 1,18-25; 5,23-45; Lc 4,113 y Jn 19,28-42) realizadas por Peters, C., «Proben eines bedeutsamen arabischen Evangelientextes», Oriens Christianus, 33 (1936), 188-211, sobre todo las 196-211; cfr. Padwick, C. E., «Al-Ghazali and the Arabic Versions of the Gospels...», Muslim World, XXIX (1939), 130140; Metzger, B. M., «Early Arabic Versions of the New Testament», en: Black, M.; Smalley, W. (Eds.), On Language, Culture and Religion: in Honor of Eugene A. Nida, La Haya-París, 1974, 159 y Metzger, B. M., The Early Versions of the New Testament, 260.

${ }^{26}$ Cfr. por ejemplo, Pines, S., «Gospel Quotations and Cognate Topics in Abd al-Jabbār's Tathbit in Relation to Early Christian and Judaeo-Christian Readings and Traditions», Jerusalem Studies in Arabic and Islam, 9 (1987), 195-278 con abundante material canónico y apócrifo; sobre «las inconsistencias de los Evangelios» de Ibn Hazm, $c f r$. una traducción parcial de Burman en la obra recopilatoria Medieval Iberia. Readings from Christian, Muslim and Jewish Sources. Edited by Olivia Remie Constable, Filadelfia, 1997, 81-83, y que en toda su amplitud y con abundantes citas evangélicas, aunque con alguna omisión, puede verse en la traducción que realizara Asín Palacios, M., Abenházam de Córdoba y su Historia crítica de las ideas religiosas. 5 vols. Madrid, 1984; otro caso, neotestamentario aunque no evangélico pero enormemente importante para lo que nos ocupa, es la cita de la «Epístola de Santiago» $(1,17)$ que nos recoge el célebre médico cordobés Ibn Ŷulŷul (cfr. Ibn Ŷulŷul, Kitāb tabaqāt al-aṭibbā' wa-l-hukamā'. Ed. de Fu'ād Sayyid, El Cairo: Institut Français d'Archeologie Orientale du Caire, 1955, 3). Un último ejemplo, perteneciente al siglo XIII, nos lo ofrece la abundancia de citas neotestamentarias (también veterotestamentarias) recogidas por el Imām al-Qurțūbī, al-

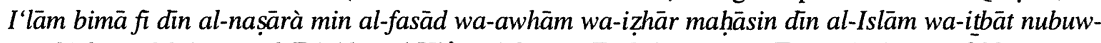
wat Nabì-nā Muhammad. Ed Ahmad Hiŷāzī l-Saqqā, El Cairo: Dā̉r al-Turāt al-'Arabī, $19 \overline{80}$.

${ }^{27}$ Entre las ediciones de Evangelios de procedencia oriental, cabe señalar las clásicas de Lagarde, P. de, Die Vier Evangelien arabisch, Osnabrück, 1972 (=Leipzig, 1864) y Levin, B., Die griechischarabische Evangelien-Übersetzung Vat. Borg. Ar. 95 und Ber. Orient. oct. 1108, Uppsala, 1938.

${ }^{28}$ Guidi, I., «Le traduzioni degli Evangeli...», 29.

${ }^{29} \mathrm{Cfr}$. el caso de las diversas citas del Salterio en latín y aljamiado editado por W. Hoenerbach. Spanisch-islamische Urkunden aus der Zeit der Nașriden und Moriscos, Bonn, 1965, 298-300. 
De las tres primeras versiones árabes de los Evangelios (aunque sin descartar del todo la atribuida al enigmático obispo Juan Hispalense en el siglo VIII ${ }^{30}$ ) realizadas en al-Andalus, una de ellas (con la que, en opinión de algunos, guardan relación, de forma directa o indirecta, cuatro de las seis copias que nos han llegado) es obra de un cristiano arabizado de Córdoba, un tal Ishạa b. Balašk ${ }^{31}$ (Isaac el de Velázquez/Blázquez/Velasco/Blasco), que en el año 946 realizó una traducción (tarŷama sanat sitta wa-arba 'in wa-tis 'a mi'a 'alà yaday Is ḥāq b. Balašk al-Qurțubi rahima-hu Allāh ${ }^{32}$ ) de los Evangelios a partir de un antiguo texto latino fuertemente influenciado por la Vulgata (Seine Vorlage war eine Hs. mit dem altlateinischen Evv-Text, der stark durch die Vulgata beeinflußt war) con elementos procedentes del Diatessaron de Taciano ${ }^{33}$ y con calcos idiomáticos musulmanes según van Koningsveld ${ }^{34}$, sólo superada hasta este momento en antigüedad - y ello a falta de nuevos hallazgos que prueben otra cosa- por los Evangelios conservados en el ms.

${ }^{30}$ Monferrer Sala, J. P., «De nuevo sobre Iohannes Hispalensis y la primera versión árabe de las "Sagradas Escrituras", realizada en al-Andalus», Revista del Instituto Egipcio de Estudios Islámicos, 31 (1999), 77-105.

${ }^{31}$ Sobre la serie de manuscritos que parece conformar esta familia textual, Roisse, Ph., «Los Evangelios traducidos del latín al árabe por Ishāa b. Balašk al-Qurțubī en 946 d. C.», en: Castillo, C.; Cortés, I., Monferrer, J. P. (Eds.), Estudios árabes dedicados a D. Luis Seco de Lucena (en el XXV aniversario de su muerte). Granada, 1999, 147-164

${ }^{32}$ Según recoge una nota colocada al comienzo del Evangelio de Lucas del ms. Aumer 238 de Múnich, que también aparece en el ms. de la Catedral de León, Guidi, I., «Le traduzioni degli Evangeli...», 28-29; $c f r$. Levi della Vida, G., «Los mozárabes entre Occidente y el Islam», Qurțba, 2 (1997), 313 (versión española).

${ }^{33}$ Graf, G., Geschichte der christlichen arabischen Literatur, I, 167; cfr. Vollers, K.; Dobschütz, E. von, «Ein spanisch-arabisches Evangelienfragment», Zeitschrift der Deutschen Morgenländischen Gesellschaft, 56 (1902), 643-648; Fraenkel, S., «Zu dem spanisch-arabischen Evangelienfragment», Zeitschrift der Deutschen Morgenländischen Gesellschaft, 57 (1903), 201; Baumstark, A., «Markus kap. 2 in der arabischen Übersetzung des Isaak Velasquez veröffentlich und unter dem Geschichtspunkt des Zusammenhangs mit dem Diatessaron Gewürdigt», Oriens Christianus, 57 (1934), 227; Taeschner, F., «Die monarchianischen Prologe zu den vier Evangelien in der spanisch-arabischen Bibelübersetzung des Isaak Velaskez nach der münchener Handschrift Cod. Arab. 238. Herausgegeben und Übersetzt», Oriens Christianus, 58 (1935), 80-99; Peters, C., Das Diatessaron Tatians, 175-177; Metzger, B. M., The Early Versions of the New Testament, 260; Assfalg, J., «Arabische Bibelübersetzungen», en: Bautier, R. H.; Auty, R. (eds.), Lexikon des Mittelalters, Múnich-Zúrich, 1983, II, col. 95; Assfalg, J., «Mozarabes», Assfalg, J.; Krüger, P. (Diss.), Petit Dictionnaire de l'Orient Chrétien. Traduction de J. Longton, Brepols, 1991, 388 y Urvoy, M. Th., «La culture et la littérature arabe des chrétiens d'al-Andalus», Bulletin de Littérature Ecclésiastique, XCII (1991), 267. Cfr. además, van Koningsveld, P. Sj., The Latin-Arabic glossary of the Leiden University Library. A contribution to the study of Mozarabic manuscripts and literature, Leiden, 1977, 54-56 y 61-62.

${ }^{34}$ Van Koningsveld, P. Sj., The Latin-Arabic glossary, 55 y van Koningsveld, P. Sj., «Christian Arabic literature from medieval Spain: An attempt at periodization», Khalil Samir, S.; Nielsen, J. S., Christian Arabic Apologetics during the Abbasid Period, 750-1258, Nueva York-Colonia, 1994, 216-217. 
4971 de Madrid ${ }^{35}$ y un fragmento de un manuscrito árabe-latino ${ }^{36}$ de la «Epístola a los Gálatas» (cuyos dos textos, independientes entre sí, han sido datados por procedimientos paleográficos como una copia de finales del siglo IX o comienzos del $\mathrm{X}^{37}$ ), que constituyen la muestra más arcaica que poseemos de una versión árabe (cuando menos parcial) de los libros del Nuevo Testamento ${ }^{38}$, pues las citas del Antiguo Testamento recogidas por el Fișal del cordobés Ibn Hazm (994-1064) pertenecen a la tradición textual oriental, tal vez a la traducción del judío egipcio del Fayyūm Še‘adyâ ha-Ga'ôn $( \pm 892-942){ }^{39}$. Tenemos, por lo tanto, en principio, varias tradiciones textuales distintas del «Padre nuestro» en árabe, unas orientales (la más antigua de finales del siglo IX) y otras occidentales (la más antigua podría remontarse a mediados del siglo $\mathrm{x}$ ), que nos sirven para conocer las lecturas más antiguas en árabe que tenemos de esta concisa oración.

Antes de entrar a analizar las versiones más antiguas que tenemos, tanto orientales como occidentales, del «Padre nuestro» en árabe, es necesario conocer la naturaleza de las dos versiones griegas del mismo. La existencia de dos redacciones del «Padre nuestro» (Mt 6,9-13 y Lc 11,2-4) datables del último tercio del siglo I (c. 75-85) y explicables como textos oracionales (de importante uso litúrgico, ya atestiguado al menos desde el siglo $\mathrm{IV}^{40}$ ) pertenecientes a dos iglesias

${ }^{35}$ De Bruyne, D.; Tisserant, E., «Une feuille arabo-latine de l'Épître aux Galates», Revue Biblique, 7 (1910), 329.

${ }^{36}$ Sobre la versión latina de la «Epístola a los Gálatas» y su relación con el texto griego, Lagrange, M. J., «La Vulgate latine de l'Épître aux Galates et le texte grec», Revue Biblique, XIV (1917), 424-450.

${ }^{37}$ De Bruyne, D.; Tisserant, E., «Une feuille arabo-latine...», Revue Biblique, 7 (1910), 324, cfr. 330; cfr. además van Koningsveld, P. Sj., The Latin-Arabic glossary, 56 y Riosalido, J., «Nuevo estudio del manuscrito mozárabe de Sigüenza», Boletín de la Asociación Española de Orientalistas, XXIX (1993), 119-129.

${ }^{38}$ De Bruyne, D.; Tisserant, E., «Une feuille arabo-latine...», Revue Biblique, 7 (1910), 328, cfr. 335.

${ }^{39}$ Cfr. Levi della Vida, G., «Los mozárabes...», Qurțuba, 2 (1997), 313. Sobre las versiones árabes del Pentateuco de S̆e‘adyâ, Bodenheimer, L., "Das Paraphrastische der arabischen Ueberse $\beta$ ung des R. Saadia Gaon», Monatschrift für Geschichte und Wissenschaft des Judenthums, 4 (1855), 23-33; Derenbourg, J., Oeuvres complètes de R. Saadia Ben Joseph el-Fayyûmi, París, 1893, tomo I ( $c f r$. Schmield, A., «Randbemerkungen zu Saadia's Pentateuchübersetzung, ed. Derenburg», Monatschrift für Geschichte und Wissenschaft des Judenthums, 45 (1901), 124-129 y Bacher, W.; Cohn, D. J., «Zu Saadja's Pentateuchübersetzung», Monatschrift für Geschichte und Wissenschaft des Judenthums, 45 (1901), 565-566; Edelmann, R., «On the Arabic Versions of the Pentateuch», en: Studia Orientalia Joanni Pedersen Septuagenario dicata, Hauniae, 1953, 71-75 y Graf, G., Geschichte der christlichen arabischen Literatur, I, 101-103. Cfr. además Monferrer, J. P., «Algunos hapax legomena, sententiae raras verbaque en el Génesis del Pentatevchvs Mosis Arabicè de la "Escuela de Estudios Árabes" de Granada", en: Castillo, C. et alii (eds.), Estudios árabes dedicados a D. Luis Seco de Lucena, 121-122 y nota 6.

${ }^{40}$ Leclercq, H., «Oraison dominicale», en: Cabrol, F.; Leclercq, H. (Dirs.), Dictionnaire d'Archéologie Chrétienne et de Liturgie, XII/2, cols. 2245-2247. 
distintas, prueba que dicha oración había sido transmitida por medio de dos redacciones que coincidían en lo esencial, pero advirtiendo la extensión mayor del texto de Mt, además de algunas variantes de interés entre ambas redacciones y la finalidad catequética distinta que persigue cada redacción ${ }^{41}$. Reproducimos, a continuación, las dos versiones para luego esbozar una serie de consideraciones de interés para las traducciones árabes:

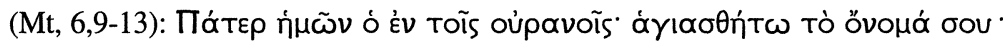

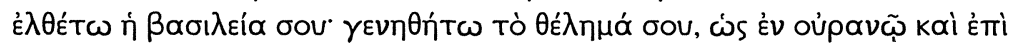

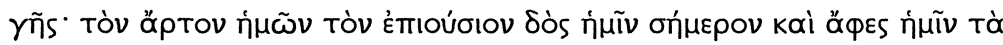

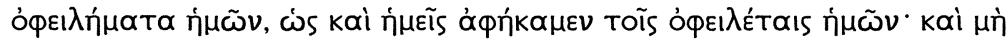

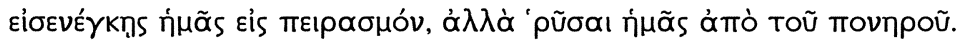

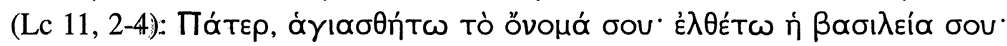

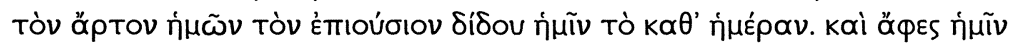

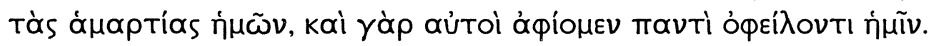

El texto de Mt recoge siete precisiones, frente al lucano que sólo incorpora cinco, de acuerdo con la tradición manuscrita más antigua. Por otro lado, la conocida e intrincada problemática de cuál de los dos textos presenta la redacción más antigua, puede responderse sin temor a caer en el error, pero no sin andar pese a ello con cierta cautela por estos ámbitos de la crítica textual. Dado que la redacción de Mt es más larga que la de Lc y esta última está contenida en aquélla, no cabe duda de que la muestra lucana representa la redacción más antigua que poco después quedó expandida por el texto de Mt sirviéndose de recursos estilísticos. Sin embargo, con esta afirmación de carácter global no agotamos del todo el problema. Así, cuestiones de crítica textual interna ponen al descubierto que determinadas secuencias y términos demuestran, no sólo que la procedencia de ambas redacciones es distinta, sino que Mt contiene elementos más arcaicos u originales que la de Lc. Por ejemplo, la lectio «nuestro pan para mañana dánoslo hoy» (Mt 6,11), articulada sobre la antítesis mañana/hoy, tiene su contrapunto en la lucana «nuestro pan para mañana dánoslo cada día», que hace desaparecer la antítesis mañana/hoy proyectándola en el tiempo. Esa amputación aspectual ${ }^{42}$ de carácter dinámico habla, por lo tanto, en favor de la

${ }^{41}$ Para la recepción, interpretación y comentario del «Padre nuestro» en la antigüedad cristiana y en la tradición griega y latina, von Stritzky, M. B., Studien zur Überlieferung und Interpretation des Vaterunsers in der frühchristlichen Literatur, Münster, 1988.

${ }_{42}$ Acerca del aspecto verbal de la koinê neotestamentaria, Mateos, J., El aspecto verbal en el Nuevo Testamento, Madrid, 1977; Leclercq, H., «Oraison dominicale», Cabrol, F.; Leclercq, H. (Dirs.), Dictionnaire d'Archéologie Chrétienne et de Liturgie, XII/2, cols. 2249-2250. 
arcaicidad del texto de $\mathrm{Mt}^{43}$. Otro ejemplo viene dado por la lectio «perdónanos nuestras deudas» (Mt 6,12a) que Lc lee «perdónanos nuestros pecados» (Lc 11,4a). Esa bina deudas/pecados opera en favor de Mt al probar el sustrato arameo del mismo ${ }^{44}$ : es conocida la peculiaridad de que el arameo emplea el término חובה/חובא (hôba'/hôbbâ: «deuda monetaria» ${ }^{45}$ ) para referir el concepto de «pecado» entendido como «deuda (económica) que debe ser saldada». En cambio, Lc se ve forzado a sustituir el concepto «deuda», que resultaba ininteligible en griego aplicado a este contexto con el sentido de «pecado», lo que también prueba que la mayor arcaicidad de la lectura de Mt es la original, arcaicidad que corrobora la segunda parte de ese mismo versículo de Lc $(11,4 b)$ que nos sirve para introducir el último caso. La lectio de Mt «así como también nosotros hemos perdonado a nuestros deudores» (Mt 6,12b) tiene la contrapartida lucana «pues también nosotros perdonamos a todo el que nos debe». En la variante aspectual de perfectivo/imperfectivo que ofrece «hemos perdonado»/«perdonamos», el aspecto es el mismo en ambas redacciones, sólo que el texto de Mt ha traducido literalmente el original arameo que empleaba un perfecto histórico; Lc lo único que hizo es evitar esa peculiariedad aramea que resultaba ambigua, adaptándola con el correcto imperfectivo para la adecuada intelección de los cristianos de lengua griega. Dicha peculiariedad aspectual también prueba, por lo tanto, que la redacción lucana ha introducido un elemento, tal como lo demuestra la lectura más arcaica representada por $\mathrm{Mt}^{46}$. Así, pues, podemos concluir con una doble observación sobre las dos redacciones del «Padre nuestro»: desde el punto de vista de la extensión del texto, la muestra lucana representa la redacción más antigua, pero

43 Dalman, G., Die Worte Jesu. Mit Berücksichtigung des nachkanonischen jüdischen Schrifttums und der aramäischen Sprache, Darmstadt, 1965 (=Leipzig, 1930²), 321-334.

${ }^{44}$ El trabajo cumbre que estudió y analizó el sustrato arameo del Nuevo Testamento (Evangelios y Hechos de los Apóstoles) es el clásico de Black, M., An Aramaic Approach to the Gospels and Acts. With an Appendix on The Son of Man by Geza Vermes, Oxford, 1971 (3. ${ }^{\mathrm{a}}$ ed. = Oxford, 1946). Esta idea del sustrato arameo sigue siendo reclamada desde distintos posicionamientos, por ejemplo, entre otros, los constructivos y enriquecedores planteamientos, desde la tradición siriaca, de Charlesworth, J. H., «Semitisms in the New Testament and the Need to Clarify the Importance of the Syriac New Testament», en: Muñoz León, D. (Ed.), Salvación en la Palabra. Targum-Derash-Berith. En memoria del Profesor Alejandro Díez Macho, Madrid, 1986, 633-638 y Lyon, J., Syriac Gospel Translations: A Comparison of the Language and Translation Method Used in the Old Syriac, the Diatessaron, and the Peshitto, Lovaina, 1994.

${ }^{45}$ Jastrow, M., A Dictionary of the Targumin, The Talmud Babli and Jerushalmi, and the Midrashic Literature. With an Index of Scriptural Quotations, 2 vols. en 1, Jerusalén: Hôreb, s.d. (=Nueva York, 1959²) I, 429; Sokoloff, M., A Dictionary of Jewish Palestinian Aramaic, RamatGan: Bar Ilan University, 1992², 189; Payne Smith, R., A Compendious Syriac Dictionary. Founded upon the Thesaurus Syriacus of R. Payne Smith edited by Jessie Payne Smith (Mrs. Margoliouth). Oxford, 1903, 129, Brockelmann, K., Lexicon Syriacum, 2. ${ }^{\text {a }}$ ed., Nueva York, 1995, 218.

${ }^{46}$ Para estas dos lecturas, Dalman, G., Die Worte Jesu..., 334-344. 
desde el punto de vista de las lecturas de los conceptos fundamentales del texto es Mt el que contiene la lectura más cercana al seguro original arameo.

Volviendo de nuevo a las distintas versiones árabes del «Padre nuestro» decíamos que, cuando menos, éstas nos permiten remontarnos al siglo IX, gracias a las versiones que los melquitas llevaron a cabo en los primeros momentos de la ocupación musulmana del solar palestinense, cuando a través de la creación de una suerte de lingua franca literaria ${ }^{47}$, una koinê que en el medio palestinense (en las lauras de Mār Sābā, Mār Jārițōn y Santa Catalina sobre todo) va a sustituir a las dos lenguas en uso, el siriaco y el griego, los instrumentos lingüísticos de que se valía la población siriaca calcedoniana antes de la llegada de los árabes, que extenderá su influencia a todos los enclaves melquitas que se hallaban repartidos por Siria, Palestina, Mesopotamia y Egipto ${ }^{48}$.

Antes de que se produjese la ocupación musulmana, la lengua empleada en las zonas urbanas y en las costeras - habitadas por melquitas ortodoxos fieles a la fe calcedoniana - era el griego, mientras que en las poblaciones del interior era el siriaco la lengua empleada. De hecho, en la inmovilista literatura litúrgica, tanto el patriarcado melquita de Antioquía como el jerosolimitano empleaban el griego (el árabe no se empleará, y además junto con el griego, hasta el siglo $\mathrm{x}$, manteniendo su empleo hasta los siglos XII-XIII en que los melquitas adoptarán definitivamente la liturgia bizantina, abandonando así el uso del griego en favor del siriaco, que no será reemplazado por el árabe hasta el siglo XVII), aunque tanto el griego como el siriaco (a nivel escrito y hablado) sólo se seguirán empleando durante los primeros momentos, hasta que en el crucial año del 750 los abbasíes se instalen en Bagdad, dando lugar a las persecuciones anticristianas e imponiendo el árabe como lengua ${ }^{49}$.

\section{VERSIONES ÁRABES ORIENTALES}

Dentro de la tradición literaria oriental cristiana en árabe, la muestra más antigua del «Padre nuestro» que poseemos, como ya hemos indicado, es la versión de

${ }^{47}$ Blau, J., «A Melkite Arabic lingua franca from the second half of the First Millenium», Bulletin of the School of Oriental and African Studies, LVII (1994), 14-16. Para el «árabe medio» empleado en las obras de los cristianos, Blau, J., A grammar of Christian Arabic. Based mainly on South-Palestinian texts from the first millenium, 3 vols. Lovaina, 1966-1967.

48 Griffith, S. H., «Eutychius of Alexandria on the Emperor Theophilus and Iconoclasm in Byzantium: a 10th-Century Moment in Christian Apologetics in Arabic», Byzantion, 52 (1982), 160-161. Para el cristianismo sirio-mesopotámico durante los dos primeros siglos del Islam, Ferré, A., «Chrétiens de Syrie et de Mésopotamie aux deux premiers siècles de l'Islam», Islamochristiana, 14 (1988), 71-106.

${ }^{49}$ Cannuyer, Ch., «Langues usuelles et liturgiques des Melquites au XIII ${ }^{e}$ s.», Oriens Christianus, 70 (1986), 111-113 y 115. 
Isțifanā l-Ramblī, la denominada Sinai Arabic Codex 72, cuya copia está fechada en las postrimerías del siglo IX (284/897), que nos documenta las siguientes:

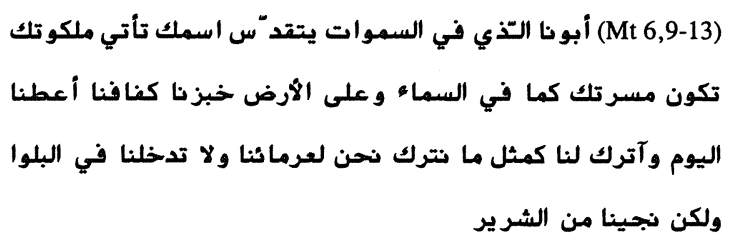

«Padre nuestro que estás en los cielos, santificado sea tu nombre. Venga Tu reino. Sea tu voluntad como en el cielo en la tierra. Nuestro pan necesario danos hoy. Déjanos como nosotros dejamos a nuestros deudores y no nos metas en la prueba, sino líbranos del Malo.»

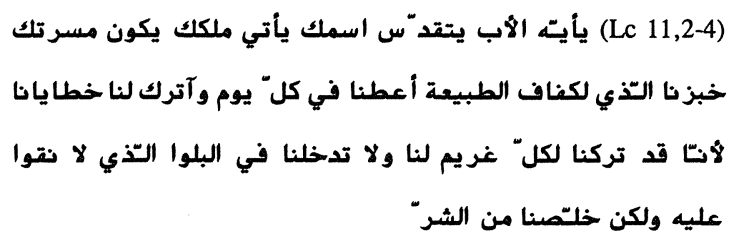

«Padre!, santificado es Tu nombre. Venga Tu reino. Sea tu voluntad. Nuestro pan necesario danos cada día. Olvida nuestras faltas, pues nosotros hemos olvidado a todos los que pecan contra nosotros, y no nos metas en la prueba que no resistamos, sino líbranos del Malo.»

La siguiente en antigüedad es la copia Vaticano Arabo 13, copiada en el Monasterio de Mār Sābā de Judea, y cuyas partes más antiguas (las restituciones son posteriores, siglo XI) datan del siglo IX, que sólo nos ha conservado la redacción de Mt, no así la de Lc:

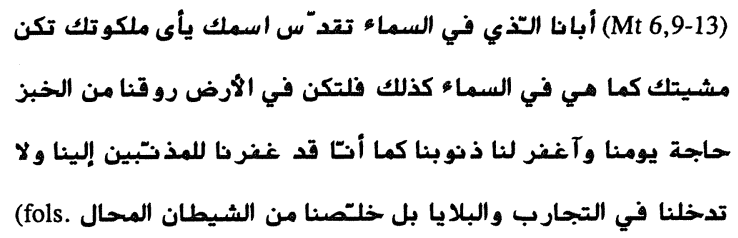

$6 r-6 v)$ 
«Padre nuestro que estás en el cielo. Santificado sea Tu nombre. Venga Tu reino. Sea Tu voluntad, cual es en el cielo asimismo sea en la tierra. Danos el pan que necesitamos cada día y perdónanos nuestros pecados, como nosotros perdonamos a los que pecan contra nosotros y no nos metas en las pruebas y las vicisitudes, sino líbranos de Satanás el Malo.»

Otra copia, fechada en el siglo XI (1065) y denominada Sinai Arabic Codex 69 , nos ha conservado en pergamino los cuatro evangelios que nos ofrecen las siguientes lecturas del «Padre nuestro»:

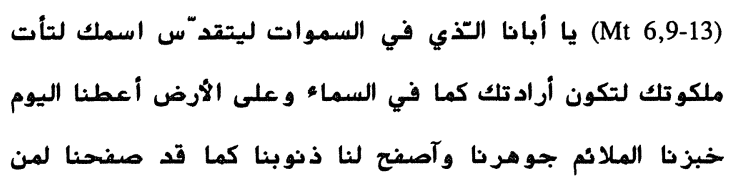

«Padre nuestro que estás en los cielos, santificado sea tu nombre. Venga tu reino. Sea tu voluntad como en el cielo en la tierra. Danos hoy nuestro pan cotidiano, nuestra sustancia. Perdónanos nuestros pecados como perdonamos a quienes nos deben, y no nos metas en prueba, sino líbranos del Malo.»

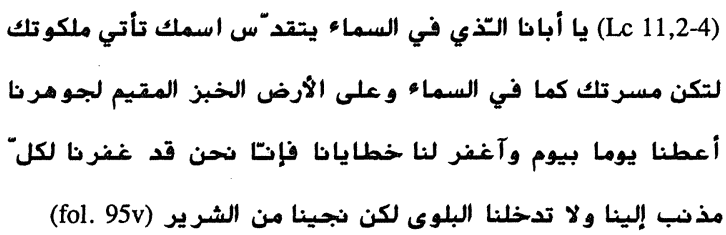

«Padre nuestro que estás en el cielo, santificado sea tu nombre. Venga tu reino. Sea tu voluntad en el cielo como en la tierra. Nuestro pan consustancial danos día tras día. Perdónanos nuestros pecados, pues nosotros ya hemos perdonado a todos los que han pecado contra nosotros, y no nos metas en la prueba, sino líbranos del Malo.»

La versión árabe del evangelio bilingüe de Lc, fechado en el siglo XI (1043) y conocido como BnF suppl. grec 911 que se conserva en la «Biblioteca Nacional de Francia» ${ }^{50}$, recoge la siguiente versión:

${ }^{50}$ De la edición de este ms., su estudio paleográfico y textual nos estamos ocupando el Prof. Ángel Urbán y yo mismo. 


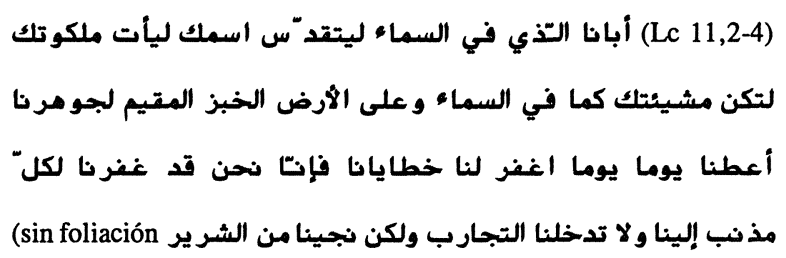

actual)

«Padre nuestro que estás en el cielo, santificado sea tu nombre. Venga tu reino. Sea tu voluntad como en el cielo en la tierra. Nuestro pan consustancial danos día tras día. Perdónanos nuestras faltas, pues nosotros ya hemos perdonado a todos los que han pecado contra nosotros, y no nos metas en las pruebas, sino líbranos del Malo.»

Dos siglos posterior, de finales del siglo XIII, es la versión que nos ha transmitido el jacobita Yuhannā b. Abī Zakariyyā' en el célebre tratado de teología dogmática y moral, de liturgia y disciplina eclesiástica que es al-Ŷawhara $l$ Nafisa («La Perla Preciosa») o Pretiosa Margarita como viene siendo denominada, el cual resulta interesantísimo por la lectura que nos ofrece ${ }^{51}$ :

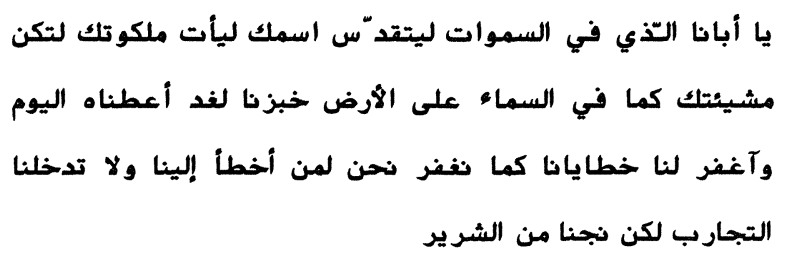

«Padre nuestro que estás en los cielos, santificado sea tu nombre. Venga tu reino. Sea tu voluntad como en el cielo en la tierra. Nuestro pan de[1] mañana dánoslo hoy. Perdónanos nuestras faltas como nosotros perdonamos a quienes nos faltan, y no nos metas en las pruebas, sino líbranos del Malo.»

La «fusión armonizada» de las redacciones de Mt y Lc que contiene el Diatessaron árabe reproduce la siguiente lectura ${ }^{52}$ :

${ }^{51}$ Périer, J., «La Perle Précieuse traitant des sciences ecclésiastiques (Chapitres I-LVI)», Patrologia Orientalis, XVI (1922), 683-684.

${ }^{52}$ Marmadji, A. S., Diatessaron de Tatien..., 86 (trad. francesa en 87). 


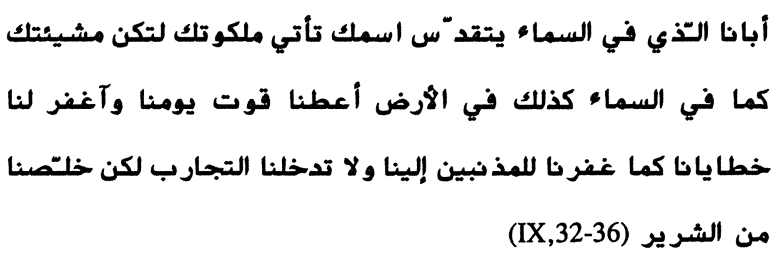

«Padre nuestro que estás en el cielo, santificado sea tu nombre. Venga tu reino. Sea tu voluntad como en el cielo así en la tierra. Danos el alimento de nuestro día. Perdónanos nuestras faltas como perdonamos a los que faltan contra nosotros, y no nos metas en las pruebas, sino líbranos del Malo.»

El Diatessaron persa, por su parte, como nos lo ha conservado el Codice Mediceo-Laurenziano XVII, una copia realizada a partir de otra más antigua y fechada el 21 de noviembre de 1547, ofrece la versión armonizada que sigue ${ }^{53}$ :

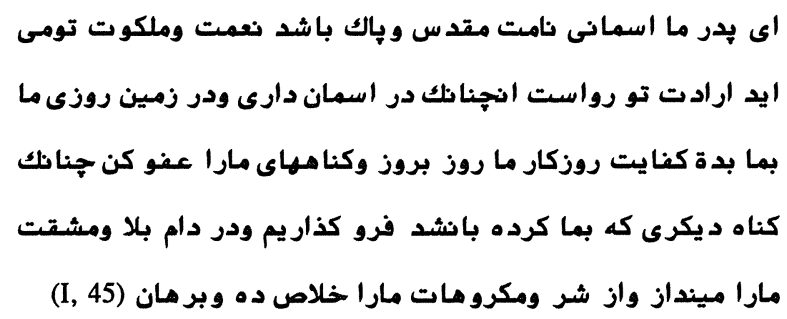

«Padre nuestro celeste, sea tu nombre santificado (bis). Venga tu reino. Sea tu voluntad, como es en el cielo en la tierra. Danos nuestro alimento necesario hoy [y] cada día, y perdona nuestros pecados, como nosotros perdonamos el pecado que los otros han cometido contra nosotros, y no nos metas en la prueba (bis), sino libéranos (bis) del Malo (bis).»

Como podemos apreciar, las variantes que se documentan son las que cabría esperar, dependientes, como es lógico, de la fuente de la que ha partido cada versión árabe. De los cuatro mss. empleados, sólo uno, Vaticano Arabo 13, es traducción de un original siriaco, los tres restantes tienen como original a un texto griego. El texto de Yuhannā b. Abī Zarakiyyā' y las dos versiones diatesarónicas

${ }^{53}$ Diatessaron persiano. Ed. di Giuseppe Messina (Biblica et Orientalia. Sacra Scriptura Antiquitatibus Orientalibus Illustrata). Roma, 1951, 70-71. Dos versiones del «Padre Nuestro» en pāzend y en sánscrito aparecen transliteradas en L. C. C., «Versions orientales du Pater-Noster», Le Muséon, XIX (1900), 253-254. 
(la árabe y la persa) proceden de un original siriaco. De todas las variantes, son sin duda la de Mt 6,11/Lc 11,3 y la de Mt 6,12a/Lc 11,4a, las más importantes tanto a nivel teológico como textual. De la primera variante sólo la versión del texto aportado por Yuhannā b. Abī Zarakiyyā' recoge una lectura etimológica acorde con el término Émıoúoıos (< arameo mahar [ [ מחר]: «mañana» ${ }^{54}$ ) a través de la fórmula jubzu-nā li-gad («nuestro pan del mañana»; la antigua versión georgiana del siglo IX [897] de Mt, por ejemplo, aduce la variante «eterno» ${ }^{55}$ ) retomando el valor proléptico que requiere la lectura del original «mañana» entendido como el «gran mañana», como el cumplimiento final en el que actúa el «pan escatológico», el «pan de vida» ${ }^{56}$, tal como lo entendían, al menos, los monofisitas ${ }^{57}$, pues la tradición melquita parece apostar desde los primeros instantes por la lectura «alimento necesario» (rizq kafăf $)^{58}$. El mismo Orígenes, examinando el significado del término, señalaba que દ̇mıúoı ningún autor griego, ni en ningún sabio, así como tampoco se documentaba en la

\footnotetext{
${ }^{54}$ Jastrow, M., A Dictionary of the Targumim..., II, 764; Sokoloff, M., A Dictionary of Jewish Palestinian Aramaic..., 301; Payne Smith, R., A Compendious Syriac Dictionary, 265; Borckelmann, Lexicon Syriacum, 381.

${ }^{55}$ Blake, R., «The Old Georgian Version of the Gospel of Matthew from the Adysh Gospels with the Variants of the Opiza and Tbet' Gospels», Patrologia Orientalis, XXIV (1933), 34. La versión lucana, en cambio, no mantiene esta lectura, Brière, M., «La Version Géorgienne ancienne de l'Évangile de Luc d'après les Évangiles d'Adich avec les variantes des Évangiles d'Opiza et de Tbet'», Patrologia Orientalis, XXVII (1957), 368.

${ }^{56}$ Sobre el término Émıúøıos, Davies, W. D.; Allison, D. C., Jr., A Critical and Exegetical Commentary on the Gospel according to Saint Matthew, Edimburgo, 1988, 607-610, espec. 609; Driver, S. R.; Plummer, A.; Briggs, Ch. A., The International Critical Commentary of the Holy Scriptures of the Old and New Testaments. A Critical and Exegetical Commentary on the Gospel according to S. Matthew by Willoughby C. Allen, Edimburgo, 1907 (2.a ed.), 59 y A Critical and Exegetical Commentary on the Gospel according to S. Luke by A. Plummer, Edimburgo, 1908 (4. ${ }^{2}$ ed.), 295-296; Hagner, D. A., World Biblical Commentary. Vol. 33A. Matthew, 1-13, Dallas, 1993, 149-150.

${ }^{57}$ Périer, J., «La Perle Précieuse traitant des sciences ecclésiastiques (Chapitres I-LVI)», Patrologia Orientalis, XVI (1922), 694. Cfr. además Khatir, A.-Burmester, O. H. S., The Horologion of the Egyptian Church. Coptic and Arabic Text from a Mediaeval Manuscript, El Cairo, 1973, 1 (texto árabe) y 1 (texto copto), y La santa salmodia annuale della chiesa copta. Traduzione, introduzione e annotazione di fr. Marco Brogi, o.f.m. Prefazione di Gabriele Giamberardini, o.f.m. El Cairo, 1962, 3, nota 2. Para una lectura idéntica, contenida en la explicación del Pater noster del «santo Abba Evagrio», en un manuscrito en copto bohaírico copiado a finales del siglo Ix, Caubet Iturbe, J., «La cadena coptoárabe de los evangelios y Severo de Antioquía», Álvarez Verdes, L. y Alonso Hernández, E. J. (Eds.), Homenaje a Juan Pardo. Miscelánea de Estudios Biblicos y Hebraicos, Madrid, 1975, 423. Cfr. también The Coptic Version of the New Testament in the Northern Dialect. Otherwise called Memphitic and Bohairic. Introduction, critical apparatus and literal English Translation. Oxford, 1898, I, 38 (Mt) y 154155 (Lc); The Coptic Version of the New Testament in the Southern Dialect. Otherwise called Sahidic and Thebaic with critical apparatus, literal English Translation register of fragments and estimate of the Version. Oxford, 1911, I, 44-47 (Mt) y 212-213 (Lc).

${ }^{58}$ Khalil Samir, S., «The earliest Arab Apology for Christianity (c. 750)», Khalil Samir, S.; Nielsen, J. S. (eds.), Christian Arabic apologetics..., 100. Sobre la fecha en la que fue redactado este manuscrito, Khalil Samir, S., «Une apologie arabe du christianisme d'époque umayyade?»,
} 
lengua corriente, pareciéndole más bien que fuera voz acuñada por los evangelistas ${ }^{59}$. Jerónimo, por su parte, siguiendo la lectura etimológica aramea (in auangelio quod appellatur secundum hebraeos pro supersubstantiali pane maar repperi, quod dicitur crastinum, ut sitsensus: panem nostrum crastinum, id est futurum... ${ }^{60}$ ) y reforzándola con la exégesis ('panen nostrum supersubstantialem da nobis hodie' hoc est, qui est de tua substantia. In hebraico euangelio secundum matthaeum ita habet: 'panem nostrum crastinum da nobis hodie' hoc est, panem quem daturus es nobis in regno tuo, da nobis hodie ${ }^{61}$ ) apostaba por la lectio supersubstantialem (Mt 6,11) frente a la de quotidianum aportada por Lc 11,3. En cuanto a la segunda variante, «deudas»/«pecados», sólo es resuelta satisfactoriamente en ambas versiones por Sinai Arabic Codex 72. Nos hallamos, por tanto, ante copias eclécticas que, amén de las variantes que presenta cada versión, evidencian en este punto dos lecturas distintas en estos textos capitales de la traducción bíblica en árabe.

\section{VERSIONES ÁRABES OCCIDENTALES}

Las muestras andalusíes, por otro lado, aunque posteriores cronológicamente como ya hemos señalado más arriba, también nos son de enorme interés para conocer cuál es la tradición que siguieron las versiones árabes empleadas en Occidente por los «cristianos arabizados».

El ms. de Munich, una copia del siglo xIV (1394) realizada sobre una segunda copia del XII (1145), que se conserva en la Bayerische Staatsbibliothek con la signatura $\operatorname{Cod}$. Ar. 238, junto a otro material contiene los cuatro Evangelios ${ }^{62}$ que nos han conservado las siguientes versiones:

Parole de l'Orient, 16 (1990-1991), 85-106 y Swanson, M. N., «Some Considerations for the Dating of $f i$ Tathlith Allāh al-wāhid (Sinai ar. 154) and al-Ğämi ' wağüh al-īmān (London, British Library or. 4950)», Parole de l'Orient, 18 (1993), 115-141 y «Beyond Prooftexting: Approaches to the Qur'ān in Some Early Arabic Christian Apologies», Muslim World, LXXXVIII (1998), 297-319.

${ }^{99}$ Orígenes, Oratio Dominica, 27.7, en: Koetschau, P. (ed.), Die griechischen christlichen Schriftsteller der ersten drei Jahrhunderte. Leipzig, 1899.

${ }^{60}$ Jerónimo, Commentarii in euangelium Matthaei, Lib. I, SL 77 (D. Hurst/M. Adriaen, 1969), lin. 778 (=PL 26,44CD).

${ }^{61}$ Jerónimo, Tractatus lix in psalmos, psalmus 135, lin. 72ss, SL 78 (G. Morin, 1958).

62 Van Koningsveld, P. Sj., «Christian-arabic Manuscripts from the Iberian Peninsula and North Africa: A historical Interpretation», Al-Qanțara, XV (1994), 429-431. 


$$
\begin{aligned}
& \text { (Mt 6,9-13) } \\
& \text { ملكك ولتكون أن أدتك في الأرض كما لها في السماء وآمنن علينا } \\
& \text { بخبز نا الدائم في يومنا مذا وآغفر لنا ذنوبنا كما نغفر لمن أذنب }
\end{aligned}
$$

إلينا ولا توبقنا في المحنة بل سلمنا من المكروه (fol. 12v)

«Padre nuestro, Tú que estás en los cielos, santificado sea tu nombre. Venga tu reino. Sea tu voluntad en la tierra como en el cielo. Danos nuestro pan eterno hoy. Perdónanos nuestros pecados como perdonas a quien peca contra nosotros, y no nos metas en la prueba, sino líbranos del Enemigo.»

$$
\begin{aligned}
& \text { يأبنا تقد س اسمك وليأتي ملكك ولتكن إرادتك في (Lc 11,2-4) } \\
& \text { الأرض كما هي في السماء وآعطنا في مذا اليوم خبزنا المياوم }
\end{aligned}
$$

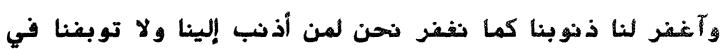

$$
\begin{aligned}
& \text { المحنة بل سلمنا من الأشر "اء (fol. 63v) }
\end{aligned}
$$

«iPadre nuestro!, santificado sea tu nombre. Venga tu reino. Sea tu voluntad en la tierra como es en el cielo. Danos hoy nuestro pan diario. Perdónanos nuestros pecados como perdonamos a quien ha pecado contra nosotros, y no nos metas en la prueba, sino líbranos de los malos.»

El ms. leonés, conservado en el Archivo de la Catedral de León con la signatura Cod. 35, que es una copia del siglo Xv (1421) realizada a partir de otra del siglo XII (1137), da las siguientes lecturas en cada una de las dos versiones:

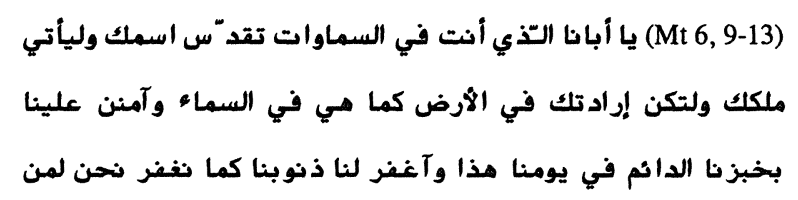

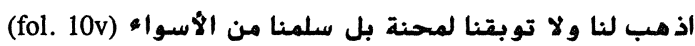

«Padre nuestro que estás en los cielos, santificado sea tu nombre. Venga tu reino. Sea tu voluntad en la tierra como es en el cielo. Danos hoy nuestro pan eterno. Perdónanos nuestros pecados como perdonamos a quien ha pecado contra nosotros, y no nos metas en prueba, sino líbranos de los malos.» 


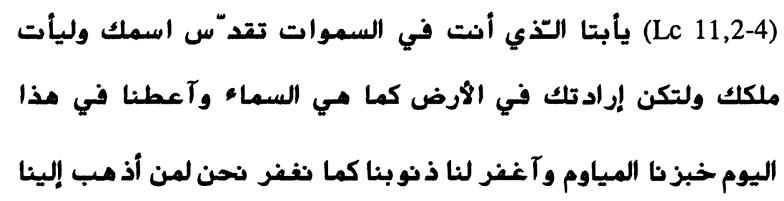

ولا توبقنا في المحنة بل سلمنا من الأسواد (fol. 176)

«¡Papaíto que estás en los cielos!, santificado sea tu nombre. Venga tu reino. Sea tu voluntad en la tierra como es [en] el cielo. Danos hoy nuestro pan diario. Perdónanos nuestros pecados como nosotros perdonamos a quienes han pecado contra nosotros, y no nos metas en la prueba, sino líbranos del Enemigo.»

El ms. londinense de la British Library, probablemente una copia del siglo XIII o XIV, que tiene la asignatura Cod. Add. 9061, sólo conserva la redacción de Mt ya que entre otros hay un vacat en el Evangelio de Lc que alcanza desde 9,43 hasta $13,35^{63}$ :

$$
\begin{aligned}
& \text { يا أبانا السماوي” تقد “س اسمك وليأت ملكك حتّى (Mt 6,9-13) } \\
& \text { تصير إرادتك في الأرض كما هي في السماء وآمنن علينا بخبزنا } \\
& \text { الدائم في يومنا هذا وآغفر لنا ذنوبنا كما نغفر نحن لمن أذنب }
\end{aligned}
$$

إلينا وآعصمنا من التشكيك وسلمنا من المكروه (fol. 11v)

«Padre nuestro celestial, santificado sea tu nombre. Venga tu reino para que sea tu voluntad en la tierra como es en el cielo. Danos nuestro pan eterno hoy. Perdónanos nuestros pecados como nosotros perdonamos a quienes han pecado contra nosotros, guárdanos del yerro y líbranos del Enemigo.»

El ms. de Fez, y a falta de un estudio pormenorizado, puede situarse en un arco temporal que va del siglo $\mathrm{x}$ al XII. Se conserva fragmentariamente en la Jizänat al-Qarawiyyīn con la signatura $\mathrm{n} .^{\circ} 730$, por lo que no disponemos de la versión de $\mathrm{Mt}^{64}$ :

${ }^{63}$ Van Koningsveld, P. Sj., «Christian-arabic manuscripts...», 436.

${ }^{64}$ Van Koningsveld, P. Sj., op. cit., 428-429; cfr. van Koningsveld, P. Sj., The Latin-Arabic glossary..., 55. 


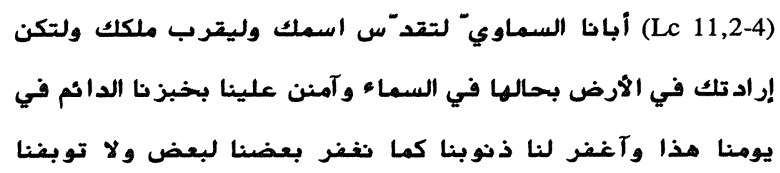

«Padre nuestro celestial, santificado sea tu nombre. Venga tu reino. Sea tu voluntad en la tierra como es en el cielo. Danos nuestro pan eterno hoy. Perdónanos nuestros pecados como unos de nosotros perdonamos a los otros, y no nos metas en la prueba, sino líbranos del Malo.»

La copia de los cuatro Evangelios (junto al Pentateuco que los precede) contenidos en el Cod. Ar. 234, que se guarda en la Bayerische Staatsbibliothek, copiado el año 898/1493 y ejemplo de la circulación de material cristiano (y de procedencia cristiana) en círculos musulmanes norteafricanos ${ }^{65}$, incluye las siguientes versiones:

$$
\begin{aligned}
& \text { يأبتاه الآي أنت في السموات تقسّس اسمك وبيأتي }
\end{aligned}
$$

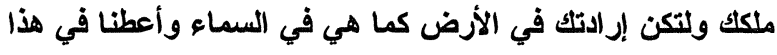

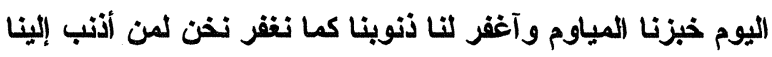

ولا توبقنا المحنة بل سلمنا من الأسواد (fol. 109v)

«Padre, tú que estás en los cielos, santificado sea tu nombre en tu reino. Sea tu voluntad en la tierra como lo es en el cielo. Danos nuestro pan eterno hoy. Perdónanos nuestros pecados como nosotros perdonamos a quienes han pecado contra nosotros, y no nos metas en la prueba, sino líbranos del Malo.»

$$
\begin{aligned}
& \text { (Lc 11,2-4) يأبتاه التي أنت في السموات تقد “س اسمك وبيأتي } \\
& \text { ملكك ولتكن إرادتك فيالأرض كما هي في السماء وأعطنا في هذا } \\
& \text { اليوم خبز نا المياوم وآغفر لنا ذنو بنا كما نغفر نحن لمن أذنب إلينا }
\end{aligned}
$$

ولا توبقنا المحنة بل سلمنا من الأسواد (fol. 109v)

«Papaíto que estás en los cielos!, santificado sea tu nombre. Venga tu reino. Sea tu voluntad en la tierra como es en el cielo. Danos hoy nuestro pan diario.

${ }^{65}$ Van Koningsveld, P. Sj., «Christian-arabic manuscripts...», 431-432. 
Perdónanos nuestros pecados como nosotros perdonamos a quienes han pecado contra nosotros, y no nos metas en la prueba, sino líbranos del Enemigo.»

La versión de los Evangelios que se halla en la Biblioteca Nacional de Madrid, catalogada como Ar. 4971, es una copia anónima y todavía sin datar (recibió añadidos en el siglo XVI) que responde a una tradición manuscrita distinta a la de Ishāq b. Balašk. Dicha copia nos ha conservado, con lagunas de interés, junto a las epístolas paulinas (salvo la «epístola a los Gálatas») la versión del «Padre nuestro» de Mt, no pudiendo contar con la de Lc ${ }^{66}$ :

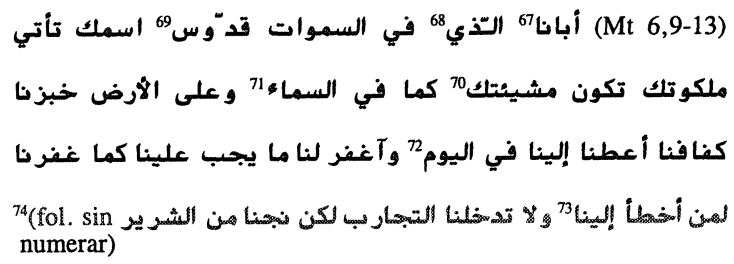

«Padre nuestro que estás en los cielos, santo sea tu nombre. Venga tu reino. Sea tu voluntad como en el cielo sobre la tierra. Nuestro pan necesario danos hoy. Perdónanos lo que debemos como perdonamos a quienes han faltado contra nosotros, y no nos metas en las pruebas, sino líbranos del Malo.»

El ms. de El Escorial, una copia del siglo XVI (1553) que responde a la signatura $\operatorname{Cod}$. 1626 y tampoco pertenece a la supuesta familia de copias que forman la tradición manuscrita de la versión de Ishạa b. Balašk, incluye las siguientes versiones ${ }^{75}$ :

${ }^{66}$ Van Koningsveld, P. Sj., «Christian-arabic manuscripts...», 437 y 445-446; cfr. van Koningsveld, P. Sj., The Latin-Arabic glossary..., 54-55.

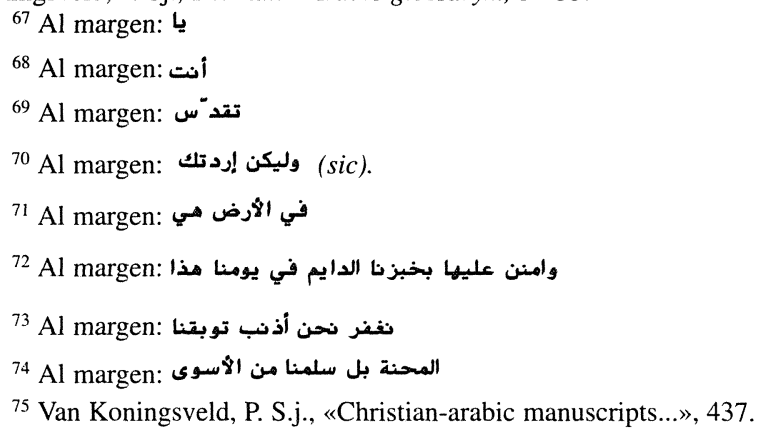

${ }^{75}$ Van Koningsveld, P. S.j., «Christian-arabic manuscripts...», 437. 


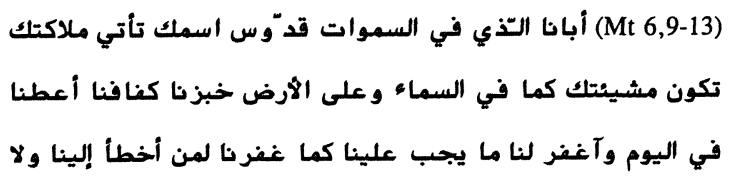

تدخلنا التجارب لكن نجنا من الشر ير (fols. 10v-11r)

«Padre nuestro que estás en los cielos, santo sea tu nombre. Venga tu reino. Sea tu voluntad como en el cielo sobre la tierra. Nuestro pan necesario danos hoy. Perdónanos lo que debemos como perdonamos a quienes han faltado contra nosotros, y no nos metas en las pruebas, sino líbranos del Malo.»

$$
\begin{aligned}
& \text { (Lc 11,2-4) أبو نا التذي في السموات يتقد" اسمك تأتي ملكوتك } \\
& \text { تكون مشينتك كما في السماء كذلك على الأرض خبزنا طميع }
\end{aligned}
$$

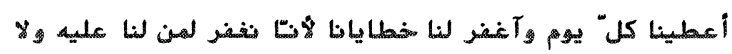

تدخلنا التجارب لكن نجنا الشرير (fols. 170r-170v)

«Padre nuestro que estás en los cielos, santificado sea tu nombre. Venga tu reino. Sea tu voluntad como en el cielo así en la tierra. Nuestro pan que esperamos danos cada día. Perdónanos nuestras faltas porque nosotros perdonamos a quienes han faltado contra nosotros, y no nos metas en las pruebas, sino líbranos del Malo.»

\section{ALGUNAS CONSIDERACIONES A LA LUZ DE LAS VERSIONES ÁRABES OCCIDENTALES DEL «PADRE NUESTRO»}

Resultan de interés las distintas versiones árabes occidentales del «Padre nuestro» que acabamos de dar porque como se puede observar pertenecen a tradiciones textuales distintas. La lectura de Mt 6,11 como «pan eterno» (=«del mañana») está documentada por las versiones de Cod. Ar. 238 y Cod. Ar. 234 de la Staatsbibliothek de Munich (jubzu-nā l-dā'im), el Cod. 35 del Archivo de la Catedral de León (jubzu-nā l-dā'im) y por el Cod. Add. 9061 de la British Library de Londres (jubzu-nā l-dā'im); la de Lc 11,3, asimismo como «pan eterno», sólo es recogida por la copia de Fez 730 (jubzu-nā l-dā'im) y por la variante «nuestro pan que esperamos» (jubzu-nā tamī') de la copia de El Escorial.

El hecho tiene su importancia porque, si observamos las versiones latinas que damos en apéndice, las lecturas son las conocidas de panem nostrum supersubstantialem/cot(t)idianum $(\mathrm{Mt})$ y panem nostrum cot(t)idianum $(\mathrm{Lc})$, de acuerdo con la tradición latina occidental que se mantiene en copias aljamiadas de los moriscos 
valencianos del siglo XVI (dos castellanas: il-ban nuwišturu di qā d̄a diya/il-bān nuwišsturū d̦i qazā diyah; y una latina: banim nuštirum qutidiyanum) ${ }^{76}$, que en modo alguno coinciden con las lecturas etimológicas que acabamos de referir. Nos hallamos, pues, ante una importante variante que evidencia depender de una fuente distinta a la que representa la tradición latina. Pudiera ser que el autor (aunque no habría que descartar que pudieran haber participado en la traducción varios individuos a la orden de una persona) hubiera consultado algún texto griego interpretando de este modo el término ĖTıoúcios, pero tal vez lo más verosímil sea suponer que algún cristiano oriental monofisita (si no algún texto) pueda estar detrás de las traducciones árabes de los textos neotestamentarios de los «cristianos arabizados» andalusíes. En cuanto a la segunda variante, «deudas»/«pecados» (Mt $6,12 \mathrm{a} / \mathrm{Lc} 11,4 \mathrm{a}$ ), la lectura original de «deudas», que es la que ofrecen las versiones latinas (debita), sólo es seguida por la paráfrasis del Ar. 4971 de la Biblioteca Nacional de Madrid y el Cod. 1626 de El Escorial.

La cuestión no es baladí porque, como se sabe, aquellos que se han venido ocupando sucesivamente de las versiones árabes occidentales del Nuevo Testamento siempre han partido (con acusada reiteración) del axioma de que estas versiones son el producto de una traducción efectuada sobre la base de un texto latino (Vetus/Vulgata), tal como hemos señalado más arriba. No es que yo pretenda negar, de raíz, esta afirmación, pero sí matizarla en extremo y ponerla en cuarentena a la luz de estas dos lecturas a las que acabamos de referirnos, e incluso de otras pertenecientes a otros lugares de los Evangelios a las que no es el momento oportuno de acudir. Los análisis traductológicos efectuados han sido siempre parciales y, amén de los un tanto ligeros intentos de filiación de fragmentos diatesarónicos perseguidos por Baumstark fundamentalmente, siempre se han basado en comparaciones aisladas (isolated) entre un texto árabe y otro latino, sin recurrir a un posible tercer texto (griego, árabe, siriaco o copto) que actuara de «corrector» o «iluminador», mediante la ayuda de alguna persona que conociese esa tercera lengua.

El análisis traductológico deberá tener en cuenta las distintas tradiciones escriturarias latinas, pero teniendo presente, al mismo tiempo, las versiones orientales. ¿Sería muy descabellado pensar en la labor «mediadora» de algún cristiano oriental venido a al-Andalus? No hay que olvidar, tampoco, que tra-

\footnotetext{
${ }^{76}$ Labarta, A., «Oraciones cristianas aljamiadas en procesos inquisitoriales de moriscos valencianos», Boletín de la Real Academia de Buenas Letras de Barcelona, XXXVII (1977-1978), 183, 193 y 196 respectivamente. Cfr. el texto «readaptado» del Miftāh al-Dīn de Muhammad al-Qaysī que, con respecto a la secuencia que nos interesa, traducen van Koningsveld y Wiegers como give us our daily bread, van Koningsveld, P. Sj.; Wiegers G. A., «The polemical works of Muhammad al-Qaysī (fl. 1309) and their circulation in Arabic and Aljamiado among the Mudejars in the fourteenth century», Al-Qanțara, XV (1994), 189.
} 
ducciones latinas de un texto griego resultan, en ocasiones, idénticas a traducciones árabes de un original griego y ello, obviamente, no obliga a suponer que la traducción árabe se haya efectuado a partir de una versión latina exclusivamente. Quiero con ello decir, y estoy hablando en términos generales, que las coincidencias que presentan en muchos casos las versiones árabes y las latinas pueden ser producto de la única posibilidad traductológica existente a que obliga un texto griego. Habrá que estudiar, por lo tanto, cuál es la técnica empleada por los traductores árabes cristianos andalusíes de los textos bíblicos, cómo tratan los semitismos las versiones latinas y cómo las árabes, cómo acaban siendo vertidos los modismos, los tecnicismos, etc.

En suma, que las valoraciones de tipo global deben ser completadas con estudios sistemáticos y pormenorizados que todavía no han sido acometidos. Ello no sólo ayudará a poder descubrir el texto de partida de las distintas versiones árabes, sino a esclarecer el probable uso y mediación de otro posible material que actuó sobre la actividad traductora, contribuyendo, además, a diseñar el árbol genealógico (stemma codicum) de las posibles familias textuales con que contamos. A ello debe acompañar, asimismo, un estudio de la llegada de cristianos orientales a al-Andalus. Tal vez haya que insistir en que hubo necesidad de textos cristianos en árabe (bíblicos o de carácter polemista) desde los primeros momentos para afrontar los envites del nuevo Estado musulmán bajo el que tuvieron que vivir.

Digo esto último porque, a la luz de las distintas versiones del «Padre nuestro» se desprende una serie de cuestiones que ponen en jaque a determinadas «creencias» $\mathrm{y}$ «suposiciones» que aún vienen señoreando como axiomas inamovibles. Si observamos las distintas copias vemos cómo hay dos textos que reproducen una misma versión: se trata del Ar. 4971 de la Biblioteca Nacional de Madrid y del Cod. 1626 de la Biblioteca de El Escorial. Ambos recogen (salvo un ilay-nā expletivo ausente en el segundo) la misma versión de Mt (por desgracia la copia de la Biblioteca Nacional no nos ha conservado la versión lucana, que pudiera haber sido determinante) que a su vez diverge de las restantes. Pero esto, siendo importante, no es lo más interesante. Se ha repetido hasta la saciedad que las versiones representadas por el Cod. Ar. 238 de la Staatsbibliothek de Munich, el Cod. 35 del Archivo de la Catedral de León, el Cod. Add. 9061 de la British Library de Londres y el ms. n. ${ }^{\circ} 73$ de la Jizänat al-Qarawiyyīn de Fez, junto con el Cod. Ar. 234 de la Staatsbibliothek de Munich y el fragmento del Cod. Or. 1059B de la Universidad de Leipzig77, son especímenes manuscritos

77 Sobre este fragmento, $c f r$. Monferrer Sala, J. P., «Notula palaeographica: algo más sobre el Codex Orientalis 1059 de la Universitäts-Bibliothek de Leipzig», Qurțba, 4 (1999), 229-237. 
que forman parte de la familia perteneciente a la traducción atribuida al cordobés Ishāa b. Balašk ${ }^{78}$. Si observamos las versiones del «Padre nuestro» (en las redacciones de Mt y Lc conservadas) que nos ofrecen dichas copias, podemos ver que muestran variantes entre todas ellas que obligan a pensar en dos cosas: que un copista haya alterado la supuesta única versión de la que parten todas ellas o, lo que es más lógico desde el punto de vista textual, que obedezcan a tradiciones textuales y manuscritas distintas. Si ello es así (lecturas radicalmente distintas hay, como se puede comprobar), cabe plantearse si estas diferencias a veces tan sustanciales en un texto de una importancia capital como es el «Padre nuestro» no nos fuerzan a poner en duda la supuesta afinidad textual de todos ellos y a plantear a los mismos como textos pertenecientes a familias textuales y manuscritas distintas. Diversidad textual y manuscrita que se enriquece con la genuina y única versión incluida en el Maqāmi ‘ al-ṣulbān de al-Jazraŷî, distinta a todas las anteriores y muestra de la citada diversidad del corpus de textos neotestamentarios que debieron correr por al-Andalus y más tarde por los reinos cristianos peninsulares ${ }^{79}$. Ello, evidentemente, debe ser corroborado o desestimado después de un estudio profundo, completo y detallado de dichas versiones, pero que un texto de la importancia del «Padre nuestro» ofrezca estas variantes es suficiente para poner en tela de juicio las posturas que vienen manteniéndose, obligando a replantear y renovar el estudio de las muestras representadas por dichas copias.

\section{APÉNDICE}

\section{VERSIONES LATINAS}

Las versiones que nos han conservado las distintas tradiciones manuscritas latinas recogen las variantes características de ambas redacciones, documentando los textos siguientes:

\footnotetext{
${ }^{78} \mathrm{El}$ último en reivindicar esta familia textual, asumiendo las posturas de los investigadores que le han precedido, es Roisse, Ph., «Los Evangelios traducidos del latín al árabe por Ishāq b. Balašk al-Qurțubī en 946 d. C.», Castillo, C. et alii (eds.), Estudios árabes dedicados a D. Luis Seco de Lucena, 148-149.

79 Al-Jazraŷî, Maqāmi ‘ al-ṣulbān. Ed. 'Abd al-Maŷīd al-Šarfī, Túnez: Al-Ŷāmi ‘a 1-Tūnisiyya, 1975, § 5, 34. Unas valoraciones sobre esta versión se deben a Samir Khalil, S., «Maqāmil as Sulbān...», Islamochristiana, 6 (1980), 246 (reseña a la edición).
} 
1.1. Vulgata ${ }^{80}$

(Mt 6,9-13) Pater noster qui in caelis es ${ }^{81}$ sanctificetur nomen tuum veniat ${ }^{82}$ regnum tuum fiat voluntas tu sicut in caelo et in terra panem nostrum supersubstantialem ${ }^{83}$ da nobis hodie et dimitte nobis debita nostra sicut et nos dimisimus ${ }^{84}$ debitoribus nostris et ne inducas nos ${ }^{85}$ in temptationem sed libera nos a malo ${ }^{86}$.

(Lc 11,2-4) Pater ${ }^{87}$ sanctificetur nomen tuum ${ }^{88}$ adveniat regnum tuum panem nostrum cotidianum da nobis cotidie ${ }^{89}$ et dimitte nobis peccata nostra siquidem et ipsi dimittimus omni debenti nobis et ne nos inducas in temptanionem.

\subsection{Itala 90}

(Mt 6,9-13) Pater noster qui es caelis ${ }^{91}$ sanctificetur nomen tuum adveniat ${ }^{92}$ regnum tuum fiat voluntas tua [sicut] in caelo et in terra ${ }^{93}$ panem nostrum cottidianum ${ }^{94}$ da nobis hodie et dimitte ${ }^{95}$ nobis debita [et] [peccata] nostra sicut et nos dimittimus ${ }^{96}$ debitoribus nostris et ne [inducas] [nos] nos inducas ${ }^{97}$ in temptationem ${ }^{98}$ sed ${ }^{99}$ libera nos a malo.

${ }^{80}$ Biblia Sacra iuxta Vulgatam versionem. Adiuvantibus B. Fischer, I. Gribomont, H. F. D. Sparks, W. Thiele. Recensuit et brevi apparatu instruxit R. Weber, Stuttgart, 1969, II, 1533 y 1629 respectivamente.

${ }^{81}$ Var.: es in caelis.

82 Var.: adveniat.

${ }^{83}$ Var.: cotidianum.

${ }^{84}$ Var.: dimittimus.

${ }^{85}$ Var.: nos inducas.

${ }^{86}$ Var:: malo amen.

${ }^{87}$ Var.: Patter noster qui in caelis es.

${ }^{88}$ Var.: tuum fiat voluntas tua (fiat voluntas tua sicut in caelo et in terra).

${ }^{89}$ Var.: hodie.

${ }^{90}$ Var.: Itala. Das Neue Testament in altlateinischer Überlieferung nach den Handschriften Herausgegeben von Adolf Jülicher Durchgesehen und zum druck Besougt von Walter Matzkow und Kurt Aland, Matthäus Evangelium, Berlín-Nueva York, 1972, I, 31 e Itala. Das Neue Testament in altlateinischer Überlieferung nach den Handschriften Herausgegeben von Adolf Jülicher Durchgesehen und zum druck Besougt von Walter Matzkow und Kurt Aland, Lukas Evangelium, Berlín-Nueva York, 1976, III, 127-128 para las dos redacciones.
${ }^{91}$ Var.: qui in caelis es.
${ }^{92}$ Var.: veniat.
${ }^{93}$ Var.: terram.
${ }^{94}$ Var.: supersubstantialem.
${ }^{95}$ Var.: remitte/demitte.
${ }^{96}$ Var.: remittimus/demittemus.
${ }^{97}$ Var:: passus fueris induci nos.
98 Var.: temptatione.
${ }^{99}$ Var.: set. 
(Lc 11,2-4) Pater ${ }^{100}$ sancte qui in caelis es ${ }^{101}$ sanctificetur nomen tuum veniat ${ }^{102}$ regnum tuum fiat voluntas tua ${ }^{103}$ in caelo ${ }^{104}$ et in terra panem nostrum cottidianum ${ }^{105}$ da nobis hodie ${ }^{106}$ et dimitte ${ }^{107}$ nobis debita ${ }^{108}$ nostra ${ }^{109}$ sicut et nos dimittimus debitoribus ${ }^{110}$ nostri ${ }^{111}$ et ne nos inducas ${ }^{112}$ in temptanionem ${ }^{113}$ sed libera ${ }^{114}$ nos a malo ${ }^{115}$.

\subsection{Edición pluritextual de Wordsworth-White}

La edición confrontada - sirviéndose de distintas tradiciones manuscritasde Wordsworth y White, contiene las versiones que reproducimos a continuación ${ }^{116}$. Ofrecemos la fijación del texto crítico a partir de la colación efectuada por ambos especialistas y damos en nota las variantes procedentes del Codex Brixinianus. El Cavense y el Toletanus, por su lado, no recogen variantes de interés:

(Mt 6,9-13) Pater noster qui es in caelis sanctificetur nomen tuum adveniat regnum tuum fiat voluntas tua sicut in caelo et in terra ${ }^{117}$ panem nostrum supersubstantialem ${ }^{118}$ da nobis hodie et dimitte ${ }^{119}$ nobis debita nostra sicut et nos dimittimus debitoribus nostris et ne inducas nos ${ }^{120}$ in temptationem sed libera nos a malo.

100 Var.: Pater noster.

${ }^{101}$ Var.: qui es in caelis.

102 Var.: adveniat.

${ }^{103}$ Var.: fiat voluntas tua sicut.

104 Var.: in caelis/caelos.

105 Var.: cotidianum.

106 Var.: cottidie.

107 Var.: demitte.

108 Var.: peccata.

109 Var.: debita et peccata.

110 Var.: omni/omnibus debenti/debitori.

111 Var.: nobis/nostro.

112 Var.: inducas nos.

113 Var.: temptatione.

114 Var.: liberue/liberipe.

115 Var.: ab inimico.

116 Var.: Novum Testamentum Domini Nostri Iesu Christi Latine. Secundum editionem Sancti Hieronymi ad codicum manuscriptorum fidem recensuit Iohannes Wordsworth in operis societatis adsumpto Henrico Iuliano White. Oxford, 1889-1898, I, 60 y 383-384 respectivamente.

117 Var.: terram.

118 Var.: cotidianum.

119 Var.: demitte.

${ }^{120}$ Var.: ne nos inducas. 
(Lc 11,2-4) Pater ${ }^{121}$ sanctificetur nomen tuum adveniat regnum tuum ${ }^{122}$ panem nostrum cotidianum ${ }^{123}$ da nobis cotidie ${ }^{124}$ et dimitte nobis peccata nostra siquidem et ipsi ${ }^{125}$ dimittimus omni debenti nobis ${ }^{126}$ et ne nos inducas in temptanionem ${ }^{127}$.

\section{VERSIÓN HEBREA}

La que transcribimos a continuación es la versión empleada por los cristianos de lengua hebrea ${ }^{128 .}$

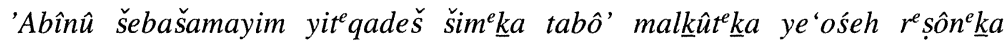

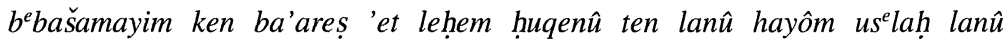

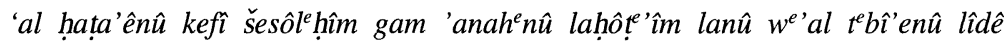
nisayôn kî 'im hal' șenû min haro'.

«Padre nuestro que estás en el cielo, santificado sea tu nombre. Venga tu reino. Sea tu voluntad, como en el cielo en la tierra. Nuestro pan dánoslo hoy, perdónanos nuestras faltas para que también nosotros perdonemos a los que nos faltan, y no nos metas en prueba, sino líbranos del Malo.»

\section{RESUMEN}

El texto que Massignon creyera ser la muestra del más antiguo «Padre nuestro» en árabe, tal como se nos ha conservado no es sino una adaptación musulmana que queda lejos de poder representar una versión directa de la Oratio Dominica, lo cual obliga a rastrear las antiguas versiones árabes del «Padre nuestro» entre la producción literaria cristiana. En ésta, tanto las versiones orientales como las occidentales ofrecen lecturas distintas en función de su procedencia doctrinal: las orientales atienden, a grandes rasgos, a una doble clasificación, muestras ortodoxas y monofisitas, en tanto que las occidentales, además de evidenciar una compleja tradición textual de los textos bíblicos neotestamentarios, parecen reflejar, cuando menos y a simple vista, interferencias orien-

121 Var.: Pater noster qui es in caelis.

122 Var.: + fiat voluntas tua sicut in caelo et in terra.

123 Var.: cottidianum.

124 Var.: hodie.

125 Var.: sicut et nos.

126 Var.: omnibus debitoribus nostris.

127 Var.: + sed erue nos a malo.

128 Seder s' 'ûdat ha'Adôn lefê min'hag Rûma', Jerusalén, 1994, 46. 
tales de procedencia monofisita, que llevan a reconsiderar la naturaleza, las fuentes y las familias textuales de las traducciones que circularon por al-Andalus.

\begin{abstract}
The text which Massignon supposed the oldest Arabic example of «Our Father», as it has been preserved for us, is a Muslim adaptation which is far from being a direct version of the Oratio Dominica, and this forces us to trace the ancient Arabic versions of the «Our Father» in the Christian literary production. Inside this literary production, Eastern and Western versions show us different readings in terms of its doctrinal origin. Eastern versions can be briefly classified in two big classes: orthodox and monophysite. On the other hand, the Western examples not only point to a complex textual tradition of the New Testament texts, but also show at first sight Eastern interferences of monophysite origin, which leads us to reconsider the kind, the sources and the textual families of the translations which were used in al-Andalus.
\end{abstract}

